\title{
MEASURING THE PUBLIC ACCEPTANCE OF URBAN CONGESTION-PRICING: A SURVEY IN MELBOURNE (AUSTRALIA)
}

\author{
Zhiyuan LIU ${ }^{1}$, Nirajan SHIWAKOTI ${ }^{2}$, Yiming BIE ${ }^{3 *}$ \\ ${ }^{1}$ School of Transportation, Southeast University, China \\ ${ }^{2}$ School of Aerospace, Mechanical and Manufacturing Engineering, RMIT University, Australia \\ ${ }^{3}$ School of Transportation Science and Engineering, Harbin Institute of Technology, China
}

Received 2 October 2014; revised 18 May 2015; accepted 17 July 2015;

published online 29 March 2016

\begin{abstract}
The practical implementations of congestion-pricing are largely restricted, due to the low public acceptance level. Based on a field survey, this study reveals the public acceptance level in Melbourne, Australia. It was found that the level of acceptance for a new congestion-pricing scheme is $42 \%$, which still needs to be improved if a congestionpricing scheme is to be implemented. Some strategies are proposed and discussed to increase the acceptance level towards congestion charge in urban cities, including an information campaign, public transport improvements and a trial.
\end{abstract}

Keywords: public acceptance, congestion-pricing, mega city, traffic congestion, field survey.

\section{Introduction}

Due to the rapid increase of population and car ownership in mega cities, traffic congestion has become a big hurdle for the further development of urban mobility and transport sustainability. Traffic congestion has largely increased the emission and fuel consumption rate of each vehicle. Traffic demand management has been well recognized to be a more efficient tool for congestion mitigation, compared with the road construction (Yang, Huang 2005; Meng et al. 2012; Wang et al. 2013). Together with parking pricing (Tezcan 2012), urban congestion-pricing is one of a few instruments for demand management, which can shift the demand from peak hour to other time (Do, Kobayashi 2000; Yang, Huang 2005). In the macroscopic transport network, it also changes the drivers' destination choice and/or route choice and prompts the usage of public transport, yielding an even and wise use of the road network (Meng and Liu, 2012).

Theoretical studies of congestion-pricing were initiated by Pigou (1920) as early as 1920. Taking the system optimum as objectives, most of the theoretical studies can be categorized into first-best pricing (with no restriction on the charging location) and the secondbest pricing (only designated locations are charged), see Lawphongpanich et al. (2006), Liu et al. (2013, 2014a).
Many other studies focus on the capacity constraints, where congestion tolls are set to restrict the total traffic flow entering one link or one area (e.g., Meng, Liu 2011; Liu et al. 2014b). Different patterns of charging are also discussed, including link-based, area-based, cordonbased, distance-based, time-based, congestion-based tolls, or their combinations and alternatives (Wang et al. 2013; Liu et al. 2014c). The charges can also be fixed or dynamically variant (Yang, Huang 2005).

However, despite a bulk of literature on the theoretical studies, the practical implementations of congestion-pricing are quite limited. Ever since first established in Singapore in 1975, sustaining and supported implementations of urban congestion-pricing only exist in a couple of cities/countries, including Singapore (Seik 2000), some Norwegian cities (Ieromonachou et al. 2006), London (Santos 2005), Stockholm (Eliasson 2008) and Milan (Rotaris et al. 2010). Nevertheless, many other schemes are terminated or abolished, including the cases in Hong Kong (Hau 1990), New York, Edinburg, Manchester and Birmingham (Hensher, Li 2013).

The introduction of a charge for the use of a road, which was previously 'free', raises equity and freedom of choice concerns while the technology used to charge the fee can create privacy issues. These issues are a subset of those lead to low public acceptance and therefore failed

*Corresponding author. E-mail: yimingbie@126.com 
implementation rates of congestion-pricing schemes. Thus, to understand and increase the public acceptance level is of significant importance to the urban congestion-pricing, prior to an attempt at implementation.

Although congestion in Melbourne, Australia is a significant issue, a congestion-pricing scheme has not yet been seriously considered and no trials or surveys have been undertaken to gauge the current level of public acceptance. This study conducts a survey in Melbourne in an attempt to measure the current level of public acceptance in regard to congestion-pricing, and subsequently provides some insights about improving its acceptance level.

\section{Literature review}

\subsection{Congestion-pricing schemes in a worldwide context}

A number of studies have been previously conducted into public acceptance of congestion-pricing. In Table 1, those studies, which have utilized survey techniques are summarized along with the key results of acceptance.

There are four cities with well-known congestionpricing schemes: Singapore (since 1975), London (since 2003), Stockholm (since 2007) and Milan (since 2012). This sub-section further reviews the congestion-pricing schemes in these cities.

Table 1. Surveys on the public acceptance of congestion-pricing

\begin{tabular}{|c|c|c|c|c|c|c|c|c|c|c|c|c|c|c|c|c|c|c|c|c|}
\hline \multirow[b]{2}{*}{ City } & \multirow[b]{2}{*}{ Year } & \multicolumn{2}{|c|}{ Nature } & \multicolumn{5}{|c|}{ Scheme type } & \multicolumn{2}{|c|}{ Type } & \multirow{2}{*}{$\begin{array}{l}\text { Analysis } \\
\text { Method } \\
\text { of analysis }\end{array}$} & \multirow[b]{2}{*}{ 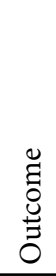 } & \multirow[b]{2}{*}{ 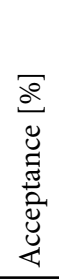 } & \multicolumn{6}{|c|}{ Issues } & \multirow[b]{2}{*}{ References } \\
\hline & & 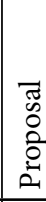 & : & 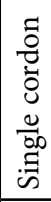 & 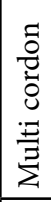 & 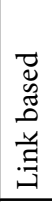 & 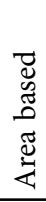 & 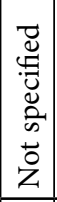 & के & 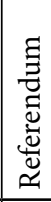 & & & & 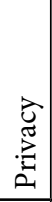 & i & 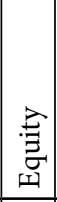 & 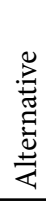 & 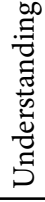 & 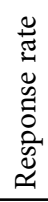 & \\
\hline \multirow[b]{2}{*}{ Edinburg } & 2002 & $x$ & & $x$ & $x$ & & & & $x$ & & $\begin{array}{l}\text { Descriptive } \\
\text { statistics }\end{array}$ & $\mathrm{R}$ & $34^{*}$ & & & & & & & $\begin{array}{l}\text { Gaunt et al. } \\
\text { (2007) }\end{array}$ \\
\hline & 2005 & $x$ & & & $x$ & & & & & $x$ & $\begin{array}{l}\text { Descriptive } \\
\text { statistics }\end{array}$ & $\mathrm{F}$ & 26 & & & & & $x$ & $x$ & $\begin{array}{l}\text { Gaunt et al. } \\
\text { (2007); } \\
\text { Hensher, Li } \\
(2013)\end{array}$ \\
\hline \multirow{3}{*}{ Stockholm } & 2005 & $x$ & & & & & & & & & $\begin{array}{l}\text { Descriptive } \\
\text { statistics } \\
\text { Regression } \\
\text { analysis }\end{array}$ & $\mathrm{R}$ & - & & $x$ & & & $x$ & & $\begin{array}{l}\text { Schuitema et al. } \\
\text { (2010) }\end{array}$ \\
\hline & 2006 & & $x$ & & & & & & & & $\begin{array}{l}\text { Descriptive } \\
\text { statistics } \\
\text { Regression } \\
\text { analysis }\end{array}$ & $\mathrm{R}$ & - & & $x$ & & & & & $\begin{array}{l}\text { Schuitema et al. } \\
\text { (2010) }\end{array}$ \\
\hline & 2006 & & $x$ & $x$ & & & & & & $x$ & $\begin{array}{l}\text { Regression } \\
\text { analysis }\end{array}$ & A & 51 & & & & & & & $\begin{array}{l}\text { Schuitema et al. } \\
\text { (2010); } \\
\text { Hensher, Li } \\
(2013)\end{array}$ \\
\hline Manchester & 2008 & $x$ & & & $x$ & & & & & $x$ & $\begin{array}{l}\text { Descriptive } \\
\text { statistics }\end{array}$ & $\mathrm{F}$ & 21 & & & & & $x$ & $x$ & $\begin{array}{l}\text { Sturcke (2008); } \\
\text { Ahmed (2011) }\end{array}$ \\
\hline Milan & 2011 & & $x$ & & & & & & & $x$ & $\begin{array}{l}\text { Descriptive } \\
\text { statistics }\end{array}$ & A & $80^{\#}$ & & & & & $x$ & & $\begin{array}{l}\text { Hensher, Li } \\
\text { (2013) }\end{array}$ \\
\hline Athens & 2008 & $x$ & & & & & & $x$ & $x$ & & $\begin{array}{l}\text { Descriptive } \\
\text { statistics; } \\
\text { Logit } \\
\text { regression; } \\
\text { Multivariate } \\
\text { probit model }\end{array}$ & $\mathrm{R}$ & 34 & & & & & $x$ & & $\begin{array}{l}\text { Rentziou et al. } \\
\text { (2011) }\end{array}$ \\
\hline \multirow{2}{*}{ New York } & 2006 & $x$ & & & & & $x$ & & $x$ & & $\begin{array}{l}\text { Descriptive } \\
\text { statistics }\end{array}$ & $\mathrm{R}$ & 44 & & $x$ & $x$ & & & & Schaller (2010) \\
\hline & 2008 & $x$ & & & & & $x$ & & $x$ & & $\begin{array}{l}\text { Descriptive } \\
\text { statistics }\end{array}$ & $\mathrm{R}$ & $67^{\wedge}$ & & & $x$ & $x$ & & & Schaller (2010) \\
\hline
\end{tabular}

Notes: ${ }^{*} 34 \%$ opted for the two cordon option as opposed to a single cordon option or no charging; ${ }^{\#} 80 \%$ voted for replacement of the Ecopass scheme with a simpler scheme (Area-C); ${ }^{\wedge} 67 \%$ supported the scheme if the revenue was used for funding public transport improvements; $\mathrm{R}$ - research only; A - accepted and implemented; F - failed and not implemented. 
Singapore implemented a cordon based, flat rate charge for motor vehicle access to the city centre in 1975 known as the Area Licensing Scheme (ALS). The initial introduction of the ALS induced to a $45 \%$ reduction in traffic entering the cordon, exceeding the target of 25-35\% (Phang, Toh 1997). Singapore government has attempted to improve public acceptance through an extensive consultation process. The scheme was adjusted through feedback prior to implementation (Goh 2002).

London introduced an area based congestion scheme in 2003. Prior to implementation, the criticism was wide spread, despite an extensive public consultation process (Santos, Shaffer 2004). The main opposition came from politicians, motorist groups and small businesses. The benefits experienced from the implementation of the scheme included significantly increased traffic speeds, reduction in taxi fares and improvement in public transport from revenue. After these benefits came into effect, the criticism was overturned. Many industries within London supported the scheme after implementation because although direct costs increased, they were outweighed by the benefits of faster deliveries and improved employee productivity (Litman 2011).

Stockholm ran a trial cordon scheme in 2006. Prior to the trial, the public opposition to the scheme included protests from politicians and motorist groups. During the trial the traffic decreased by $22 \%$ during peak periods and subsequently, the congestion and pollution levels also decreased. The public acceptance of the scheme was higher after the trial than before due to benefits exceeding the public's expectations. In addition, the costs of the scheme were not as high as the public had expected (Schuitema et al. 2010). The change in attitude was reflected in a referendum held in Stockholm after the trial in which $53 \%$ of respondents were in favour of the scheme (Eliasson 2008). A permanent scheme was introduced in 2007. An analysis of the permanent scheme found that $70 \%$ of paid charges were offset by time gains (Eliasson 2009).

Named as Ecopass, an emission pricing scheme was introduced in Milan in January 2008, aiming to primarily improve the air quality of the city, while taking congestion mitigation as a side-goal (Rotaris et al. 2010). The pricing cordon locates in central Milan, which is only 8 square kilometers, and it operates from 7:30 to 19:30. The Ecopass in Milan is not time-varying, and different vehicles types have different toll charges. There are 5 levels, and the highest daily charge is 10 Euro while the lowest is free of charge in view of the different emission level (Rotaris et al. 2010). In June 2011, according to a referendum in Milan, $80 \%$ of people support to extend the Ecopass to a new congestion charge scheme, named as Area C (Hensher, Li 2013).

Apart from these four well-known implemented case of urban congestion-pricing, there are also some trials and hypothetical schemes in many other cities, which did not gain acceptance from the majority and then ceased. For example, a pilot test was conducted in Hong Kong from 1983 to 1985, but its permanent implementation is stalled due to lack of public accept- ance. Some failure cases are also observed in New York, Manchester, Edinburgh, Cambridge, and Birmingham (De Borger, Proost 2012). Surveys on hypothetical schemes are also conducted in some cities to gauge the public acceptance on congestion-pricing, for instance, the study by Hensher et al. (2013) in Sydney.

\subsection{Melbourne context}

However, there has been no recent attempt to measure the level of public acceptance regarding congestionpricing in Melbourne. The only previous study identified was conducted in 1997 around a suburban town (Luk, Chung 1997). This study suggested that demand reductions would be relatively small at the optimal congestion toll. However, this study does not focus on the urban road tolls, and there is no other study in the past 17 years, prompting the need for further research into public acceptance of urban congestion-pricing in Melbourne.

A review of the above schemes/trials pinpointed the significance of investigating the public acceptance of urban congestion-pricing. Thus, this study works on revealing the acceptance degree of Melbourne's residents on urban congestion-pricing, which is an important initial step for its practical implementations.

Congestion has been recognized as a costly issue in Melbourne for a number of years. It has been estimated that if nothing is done in an attempt to relieve the congestion, the cost will increase from $\$ 2.7$ billion in 2001 to $\$ 8$ billion in 2020 (Clarke, Hawkins 2006).

Attempts at congestion management in Melbourne have been largely supplied and based on new road constructions. Some recent construction projects include EastLink, CityLink Upgrade, Deer Park Bypass and Pakenham Bypass. In addition to these, there is currently an investigation been undertaken for the East-West Link. However, it has been well recognized that supply based measures could not solve the traffic congestion problems because higher capacity will induce to more travel demand, and quickly using up the additional capacity (Hensher et al. 2013).

One of the only attempts at a demand based management technique in Melbourne is a parking levy which was introduced in 2006 for all long-stay parking spaces. Since the introduction of the levy, there have been increases in the number of Central Business District (CBD) commuters using public transport (Hamer et al. 2011).

Compared with many other cities in Australia, Melbourne residents are more familiar with and exposed to urban road charging schemes due to tolls in Melbourne's urban freeways (referred as CityLink). CityLink is $22 \mathrm{~km}$ long and is divided into two sections, Southern and Western Links that link a number of existing freeways to and around the CBD. The toll is electronically collected via e-tag or automatic number plate recognition, and there is no toll booth to impede the traffic flow. The toll has four different levels, categorized for car, light commercial vehicle, heavy commercial vehicle and motorcycle. The toll is distance-based, and capped at 7.87 AUD 
per trip for a car (details for other vehicle types can be found at CityLink (2014). The drivers can also buy a 24 hour license at 15.1 AUD. Weekend pass (from midday Friday to midnight Sunday) is also available at 15.1 AUD. 24 hour license and weekend pass only allow a maximum of 12 passes for one particular vehicle in 12 months (CityLink 2014).

Clarke and Hawkins (2006) previously proposed a cordon based congestion-charging scheme for Melbourne. The relatively small area of Melbourne affected by congestion makes a cordon charging scheme suitable and an area-based scheme is unnecessary due to tight parking restrictions. It is also noted that vehicles such as taxis, mopeds, motorcycles, buses and alternative fuel vehicles should not be excluded because they all contribute to the cities congestion.

Clarke and Hawkins (2006) claimed that this scheme also addresses the following issues:

- captures the majority of congestion within the CBD;

- requires approximately 20 gantries (many less than London's 200);

- through traffic could use CityLink without incurring a congestion charge;

- the majority of public hospitals, schools and emergency services are outside the boundary;

- many entertainment and shopping areas are outside the boundary.

This congestion-pricing scheme proposed by Clarke and Hawkins (2006) is a good starting point to further explore the public acceptance of congestion-charging in Melbourne. As stated in the Introduction section, there is no recent study on Melbourne residents' acceptance on congestion-pricing, so this paper aims to investigate this topic based on a field survey in Melbourne, where both Revealed Preference (RP) and Stated Preference (SP) questions are involved. The impacts of Melbourne's existing toll highways on the acceptance of a new urban congestion charge are also taken into consideration.

\section{Public acceptance measurement}

Di Ciommo et al. (2010) outlined three main methods used to estimate the public acceptance of road pricing, which are: actual behavioral changes; theoretical predictive models and questionnaires and interviews.

Actual behavioral changes can be analyzed after the implementation of a scheme or trial or through RP questions in a survey. RP questions measure behavior through asking respondents how they have reacted to situations in the past.

Theoretical predictive models are usually constructed based on the observations made from actual behavioral changes, RP questions and assumptions about behavior - e.g. Jakobsson et al. (2000). For theoretical predictive models, there are some aggregate level (e.g., modal split models) or disaggregate level (e.g., discrete choice models) methods to predict quantitatively the changes on mode shares after the implementation of any congestion-pricing schemes. Despite their theoreti- cal soundness, these models highly rely on the practical data of network attributes. However, it is extremely difficult to obtain these network data accurately, thus the results of these methods are not as reliable as real surveys. In addition, the real survey data and results are more straightforward and easy to understand.

Questionnaires and interviews are a common method used to measure public acceptance. They can be conducted in a variety of ways and a number of data analysis methods can be utilized (e.g. descriptive statistics, regression analysis and utility theory). SP questionnaire is usually used for indirect factors, such as the acceptance of congestion-pricing. SP questions obtain responses to hypothetical scenarios and have been used in transport since 1979 (Kroes, Sheldon 1988). They usually involve a number of variables and the quantity of each variable is altered to obtain a number of scenarios.

We proceed to discuss about the issues and factors affecting public acceptance of congestion-pricing. A number of issues in gaining public acceptance of a congestion-pricing scheme arise in the past, which are summarized as follows:

- perception of a need for the scheme;

- privacy issues with vehicle tracking;

- equity issues in terms of the level of access to alternative transport modes;

- equity issues in terms of the additional cost;

- level of understanding of the scheme proposed and perceived user friendliness;

- confidence that the effects will be noticeable;

- freedom of choice in transport mode;

- confidence in authoritative body to use the revenue accordingly;

- previous experience with congestion-charging schemes;

- details of the design of the scheme including level of charge and use of revenue.

The relative importance of these issues changes between cities and over time; sometimes central issues to one city are not issues at all to another. For example privacy has typically been a central issue in Asian cities (Hong Kong and Singapore) but not in London where there are many cameras monitoring the vehicles (Goh 2002; Santos 2005). In a number of cases, the issues outlined above have been ameliorated soon after implementation of a congestion scheme or a trial scheme. Examples include London (Litman 2011), Stockholm (Schuitema et al. 2010) and Milan (Rotaris et al. 2010).

Personal characteristics have sometimes been found to be substantial in determining the level of acceptance. Some commonly cited characteristics which influence acceptance are: age, income, gender, place of residence, trip characteristics (mode, origin, destination, travel time flexibility), and level of education. These factors are thus included in the questionnaire design of the survey in this study.

It should be noted that not all of these characteristics influence the level of acceptance in the population of each particular city. For example, Jaensirisak et al. (2005) found that income was not a factor influencing public 
acceptance in London; however, Rentziou et al. (2011) found that income did influence the level of acceptance in Athens. This suggests that the factors which influence congestion-pricing acceptance may vary between cities and/or through time. The result of this is that public acceptance would need to be assessed separately in each city with each proposal or implementation.

\section{Survey design}

\subsection{Questionnaire design}

The survey questionnaire consists of two parts, RP questions and SP questions. As mentioned by Hensher and $\mathrm{Li}$ (2013), an important reason that the pricing schemes in several UK cities are not supported by their referenda is because their schemes are too complicated and many voters have inaccurate information about the schemes. For example, based on a survey after the referendum in Edinburg (Gaunt et al. 2007), only $47.8 \%$ of the people knew about the correct toll fares. This largely undermined the reliability of the referendum results and the implementations of congestion-pricing. Thus, in the first page of the questionnaire used for this survey, some basic descriptions about congestion-pricing have been provided. A simple cordon-based pricing is taken as the hypothetical scheme, which is suggested based on the study in Clarke and Hawkins (2006) and is easier for the participants to follow the idea.

Following some demographic questions (age, income level, gender, etc.), the factors influencing the acceptance of congestion-pricing are added to the questionnaire, including the frequency of travelling to city area, travel modes, accessibility to cars, etc. A five-scale Likert table is used to directly measure the participants' perceptions on the hypothetical congestion-pricing scheme. In addition, a five-scale table is also included to obtain the participants' opinions on the road traffic conditions and public transport services in Melbourne. The RP survey questionnaire included following:

- revenue raised from implementing a congestion charge should be used to improve public transport services and road infrastructure;

- revenue raised from implementing a congestion charge should be used to improve the environment;

- implementing a congestion charge can help reducing traffic congestion;

- implementing a congestion charge can help protecting the environment by reducing vehicle emissions;

- implementing a congestion charge is unfair to people with lower income because they would more likely be forced not to drive to the city;

- implementing a congestion charge is not good for the economy because people would travel to the city less frequently;

- the existing public transport systems can cope with the increased volume of passengers caused by implementing the congestion charge;
- the congestion charge would make me use public transport more often for travelling to the city;

- the congestion charge would make me seek carpooling with other people more often for travelling to the city;

- the congestion charge would make me travel to the city for shopping or entertainment less frequently;

- working in the city would be a less attractive option to me because of a congestion charge;

- finally, on a 5-point scale, how strongly do you support the idea of implementing a congestion charge scheme in the Melbourne City area?

Moreover, the participants' opinions on Melbourne's toll highways were sought. To avoid suggestive cognitive influences on the other survey questions, this question regarding the toll highways is put in the end of the questionnaire. The second part of this survey comprises SP questions. There were three variables/attributes presented in the SP questions: (A) decrease in fuel cost and journey time; (B) decrease in public transport (PT) fare; $(\mathrm{C})$ congestion charge. There three variables are selected, because the major goal of congestion-pricing is to encourage mode shift from automobile to public transport, and they are the most important three components influencing the mode changing decisions.

Each variable has three possible discrete values. Table 2 summarizes these variables with the possible values and mode to which they apply. The values of each variable are determined based on the situations of current congestion-pricing schemes in other cities/countries as well as the transport system characteristics in Melbourne. First, about the 'fuel cost and journey time', in the city area, a successful congestion-pricing scheme is capable to reduce the congestion to $50 \%$; for instance, the Singapore Electronic Road Pricing scheme (Seik 2000) Hence, $50 \%$ is taken as the highest level, and 10 and $30 \%$ are taken as two stepwise values. Second, regarding the 'PT fare', the toll revenue of urban congestion-pricing schemes is usually reinvested to the transport system via subsidizing the public transports. Hence, it is reasonable to assume that with a new congestionpricing scheme, the PT fare will be reduced, where the corresponding 10,30 and 50\% are taken. Third, as to the 'congestion charge', the toll fares in other cities are taken as reference; for instance, the daily toll in London is 11.5 pounds (about \$18) and the entry-based toll in Singapore is about $3 \mathrm{~S} \$$ (about $\$ 2$ ). Therefore, the three levels of congestion charge are determined to be 5,10 and 15 dollars.

Table 2. Variables and values for the SP questions

\begin{tabular}{|c|l|c|c|c|c|}
\hline Variable & Description & \multicolumn{3}{|c|}{ Possible values } & Mode \\
\hline A & $\begin{array}{l}\text { Fuel cost and } \\
\text { journey time }\end{array}$ & $\begin{array}{c}\text { reduce } \\
10 \%\end{array}$ & $\begin{array}{c}\text { reduce } \\
30 \%\end{array}$ & $\begin{array}{c}\text { reduce } \\
50 \%\end{array}$ & Car \\
\hline B & PT fare & $\begin{array}{c}\text { reduce } \\
10 \%\end{array}$ & $\begin{array}{c}\text { reduce } \\
30 \%\end{array}$ & $\begin{array}{c}\text { reduce } \\
50 \%\end{array}$ & PT \\
\hline C & $\begin{array}{l}\text { Congestion } \\
\text { charge }\end{array}$ & $\$ 5$ & $\$ 10$ & $\$ 15$ & Car \\
\hline
\end{tabular}


A different combination of the possible values creates a unique, hypothetical scenario associated with implementing a congestion scheme. Respondents were asked how strongly they would support a congestionpricing scheme.

Together with some other recent studies on the Australian residents' perception of congestion-pricing (e.g., Hensher et al. 2013), the survey data and analytical results will provide important references to the policy making and real implementations of urban congestionpricing in Australia.

\subsection{Survey conduction}

The survey was conducted in April 2013 at 12 locations in Melbourne. Table 3 and Figure show a summary of the survey sites and response rates. A 10-dollar supermarket voucher was provided to each participant to thank for his/her time for participating in the survey. Initially, survey sessions were conducted at several locations in downtown Melbourne, as indicated in Figure. The response rate was high at Treasury Garden (site 1 in Figure) and Flagstaff Garden (site 3 in Figure) during lunchtime, because many people were generous on their time when taking a lunch break in these sites.

However, car drivers were largely under-represented from the first 2 surveys. The survey approach was adjusted, in order to attract more drivers. Some car parks in downtown area were initially tried, aiming to approach more drivers. Yet, the drivers were mostly busy heading to their working places after parking, and refused to take the interview. So, after the first four surveys, we still had very few samples from drivers. The survey strategy was further adjusted, and we decided to approach the drivers in a more casual time when they are generous on their time. Hence, two locations to the East of Melbourne (close to CityLife Church and Camberwell Road) were chosen. The surveys in CityLife Church (site 8) were conducted in four weekend days, which successfully provided high response rate and enough sample from the drivers. From Table 3, we can see that eventually 180 data points are obtained, $44 \%$ of which are drivers, and $45 \%$ of them currently take public transport to the city, while $11 \%$ take other modes (carpooling; bike and walking).

Table 3. Summary of survey sites and responses obtained

\begin{tabular}{|c|c|c|c|}
\hline $\begin{array}{c}\text { Date } \\
\text { (April 2013) }\end{array}$ & $\begin{array}{c}\text { Site } \\
\text { number }\end{array}$ & $\begin{array}{c}\text { Number } \\
\text { of responses }\end{array}$ & $\begin{array}{c}\text { Cumulative number } \\
\text { of responses }\end{array}$ \\
\hline 4 th & 1,2 & 25 & 25 \\
\hline 5 th & 2,3 & 62 & 87 \\
\hline 11 th & 4 & 10 & 97 \\
\hline 12 th & 5,6 & 26 & 123 \\
\hline 13 th & $7,8^{*}$ & 15 & 138 \\
\hline 14 th & $8^{*}$ & 3 & 141 \\
\hline 15 th & $9^{*}, 10$ & 5 & 146 \\
\hline 17 th & 11,12 & 18 & 164 \\
\hline 18 th & 7 & 3 & 167 \\
\hline 20th & $8^{*}$ & 6 & 173 \\
\hline 21 st & $8^{*}$ & 7 & 180 \\
\hline
\end{tabular}

Note: ${ }^{*}$ Site 8 - CityLife Church, 9 - Camberwell Road, both outside of the CBD.

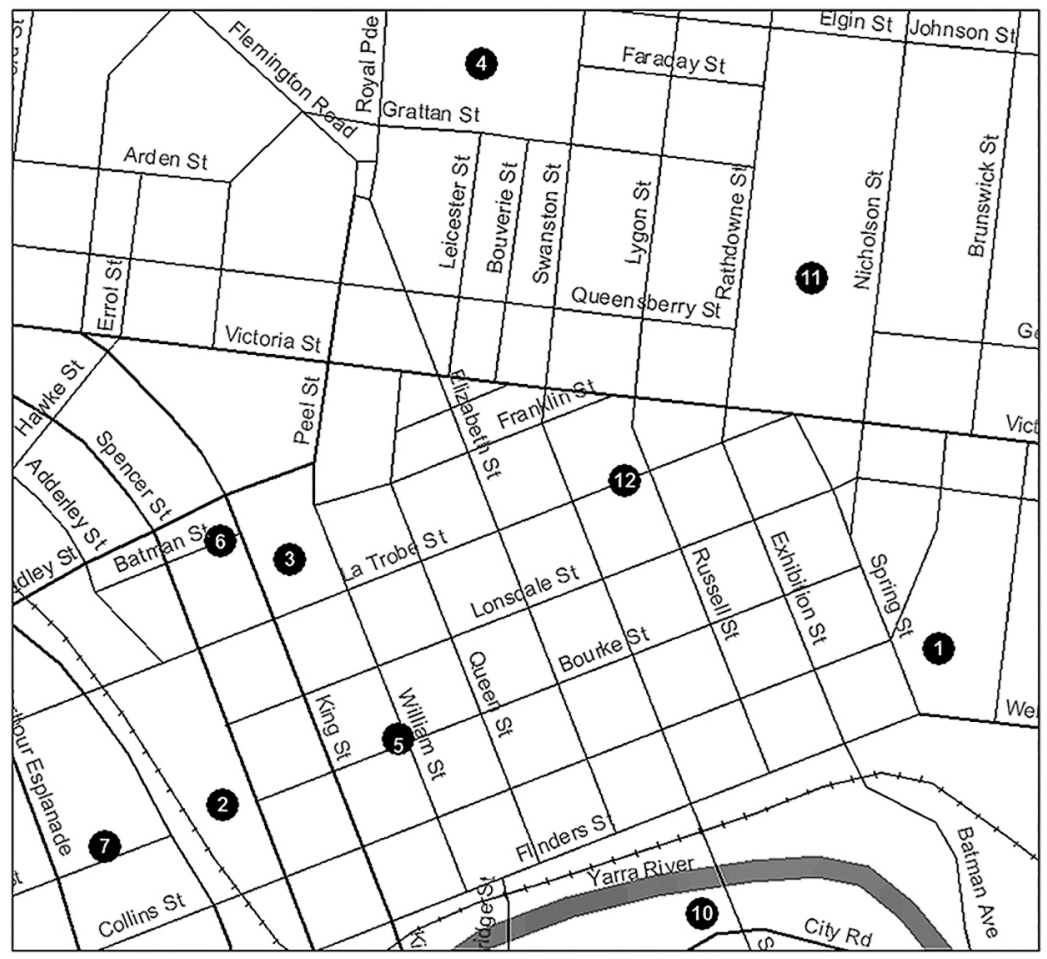

Figure. Map sites of the survey sessions in Melbourne CBD 


\section{Results and discussions}

\subsection{Data validation}

To minimize bias in the survey responses, there were four criteria that deemed a response as valid. The participants should be: (1) not a tourist, (2) travelling to the Melbourne CBD at least one day per week in peak periods, (3) not holding a conflict of interest and (4) over 18 year old, since the minimal age to get a full driving license is 17 or 18 in Australian cities.

Criteria 1 and 2 ensure that respondents have ample experience in travelling to the Melbourne CBD during peak hours, when most congestion occurs. Criterion 3 ensures that the respondent did not hold a biased view toward implementation of a congestion charge due to the nature of their (or their relatives') employment. In this survey a conflict of interest was present if the respondent, or anyone in their household, worked in market research for a car manufacturer, a public transport provider, a city rail company or the city transport department. Criterion 4 placed an age restriction of 18 on respondents to ensure they were above the legal driving age. This was necessary to minimize bias in the survey questions that required the respondent to make a mode choice (public transport or drive) in a particular scenario.

Using these criteria, we then filtered the 180 survey responses collected, and 11 were deemed unsuitable for use in the analysis based on the four criteria outline above. Therefore, the final data analysis was based on 169 survey responses. The number of responses used for analysis of individual questions varies slightly as some questions were not answered by several participants. For example, some respondents refused to provide the information about their income level.

The personal data collected include age, income, gender, race, education, employment status, car access and household type. The characteristics of age and gender were used to compare the sample to the population of Melbourne (Table 4). The number of participant using carpooling is only one, so his/her data is not included in the analysis in terms of different travel mode. The population data was obtained from Australian Bureau of Statistics (ABS 2014). The survey sample shows a close match in the gender and age data to the population in Melbourne.

In this paper, linear regression is used to analyze the survey data. As a simple regression method, the linear regression is more efficient to provide direct answers and conclusions to other researchers and readers $(\mathrm{Qu}$ et al. 2015). The results obtained from this questionnaire can be applied in three main categories, which are elabo- rated in the following sub-sections 4.1 to 4.3 . In addition, subsection 4.4 contains a discussion of additional factors and measures that were not surveyed.

\subsection{Perception of a problem with congestion in Melbourne}

The perception of a need for action is an important first step in gaining public acceptance for a congestionpricing scheme. If the public is frustrated with problems arising from congestion, it is more likely to accept a charge aimed at reducing the level of congestion (Di Ciommo et al. 2009). Hence, in the questionnaire, road users were asked to indicate their experience with congestion on a typical trip in the past six months on a five point scale, described as: 1 - Extremely Congested, 2 - Congested, 3 - Neutral, 4 - Not Congested, 5 - Not Congested at All.

The responses indicated a mean of 2.07 that is significantly lower than 3.00 (Neutral), indicating that road users typically experience congested conditions. It should be noted that there is no participant that selected 'Not Congested at All'. This result suggests that the public do perceive an issue with congestion on the roads in Melbourne and are therefore more likely to accept a congestion-pricing scheme.

\subsection{Public acceptance level of congestion-pricing in Melbourne}

The last RP question directly enquires about the participants' acceptance on a congestion-pricing scheme in Melbourne, where the five levels of acceptance are described as: 1 - Not Support at All, 2 - Not Support, 3 Neutral, 4 - Support, and 5 - Strongly Support. The last two scales indicate supportive, while the first two scales imply resistant. Table 5 shows the average percentage of each scale. We can see that in general, the supportive rate in Melbourne is $42 \%$, while the resistant rate is $38 \%$ and $20 \%$ is neutral (mean $=2.97$; SE $=0.09$ ). Such an acceptance level is similar to that in New York in 2006, and higher than the ex ante support rate in London and Stockholm (see the data in Table 8). Although the number of supportive is higher than that of resistive, such an acceptance level is still not sufficient for the practical implementation.

Table 5 also shows the acceptance rate of different travel groups, and it is not surprising to see that the general acceptance rate is: active travelers $>$ PT users $>$ car drivers. The overall acceptance rate (support + strongly support) of the active travelers is as high as $72 \%$, while this value is only $26 \%$ for the car drivers. This difference reveals that different travel groups have significantly different attitudes to congestion-pricing.

Table 4. Comparison of respondent characteristics with the population in Melbourne

\begin{tabular}{|l|c|c|c|c|c|}
\cline { 2 - 5 } \multicolumn{1}{c|}{} & Population & Total survey & Drivers & Public transport & Bike and walk \\
\hline Male [\%] & 49 & 50 & 45 & 50 & 67 \\
\hline Female [\%] & 51 & 50 & 55 & 50 & 33 \\
\hline Median age & 36 & 31 to 40 & 31 to 40 & 31 to 40 & 31 to 40 \\
\hline
\end{tabular}


Table 5. Public acceptance rate on a new scheme

\begin{tabular}{|l|c|c|c|c|}
\cline { 2 - 5 } \multicolumn{1}{c|}{} & Overall & Car driver & PT user & Bike and walk \\
\hline $\begin{array}{l}\text { Not } \\
\text { Support } \\
\text { at All }\end{array}$ & $15.2 \%$ & $28.0 \%$ & $6.7 \%$ & $0.0 \%$ \\
\hline $\begin{array}{l}\text { Not } \\
\text { Support }\end{array}$ & $22.4 \%$ & $28.0 \%$ & $17.3 \%$ & $22.2 \%$ \\
\hline Neutral & $20 \%$ & $17.3 \%$ & $25.3 \%$ & $5.6 \%$ \\
\hline Support & $34.7 \%$ & $24.0 \%$ & $41.3 \%$ & $50.0 \%$ \\
\hline $\begin{array}{l}\text { Strongly } \\
\text { Support }\end{array}$ & $7.6 \%$ & $2.7 \%$ & $9.3 \%$ & $22.2 \%$ \\
\hline Mean & 2.97 & 2.21 & 3.29 & 3.72 \\
\hline $\begin{array}{l}\text { Standard } \\
\text { Error }\end{array}$ & 0.09 & 0.09 & 0.12 & 0.25 \\
\hline
\end{tabular}

Regarding the SP questions, a multiple regression was undertaken to analyze the responses. As shown in Table 6, by taking the significant level as 0.01 , the driving costs (A), public transport fares (B) and congestion toll (C) are all significant factors (small $p$-values). It is also to be noted that the former two have larger impacts (large coefficients) than toll. However, only A and C are significant for drivers, only B and C are significant for public transport passengers, and only $\mathrm{C}$ is significant for walking and cycling commuters. Travel cost deduction for the drivers is the most influential factor among many others.

\subsection{Acceptance level of Melbourne toll highways}

In the end of the survey, the participants were asked about the acceptance of Melbourne current toll highways, and the same 5 scales were used. The toll highways give the commuters in Melbourne direct understanding of road pricing. Their opinions on the existing toll highways may affect their acceptance of a new urban congestion-pricing scheme. Hence, the participants' acceptance levels on toll highways are summarized in Table 7. We can see that the mean value for the acceptance of all the 169 participants is 3.04 , which is above average and almost the same with corresponding value in Table 5. A more significant difference between Table 5 and 7 is on the Neutral level, and it reflects that the public is more concerned about a new scheme compared with the existing urban highway tolls. These results demonstrate that the acceptance level of the general public will increase when a pricing scheme has been implemented after experiencing the benefits brought by the pricing scheme. This finding is similar to that observed in London and Stockholm.
Table 7. Public acceptance rate on existing highway tolls

\begin{tabular}{|l|c|c|c|c|}
\cline { 2 - 5 } \multicolumn{1}{c|}{} & Overall & Car driver & PT user & Bike and walk \\
\hline $\begin{array}{l}\text { Not } \\
\text { Support } \\
\text { at All }\end{array}$ & $7.4 \%$ & $12.7 \%$ & $4.1 \%$ & $0.0 \%$ \\
\hline $\begin{array}{l}\text { Not } \\
\text { Support }\end{array}$ & $20.9 \%$ & $25.4 \%$ & $16.4 \%$ & $16.7 \%$ \\
\hline Neutral & $39.3 \%$ & $35.2 \%$ & $38.4 \%$ & $61.1 \%$ \\
\hline Support & $25.2 \%$ & $18.3 \%$ & $32.9 \%$ & $22.2 \%$ \\
\hline $\begin{array}{l}\text { Strongly } \\
\text { Support }\end{array}$ & $7.4 \%$ & $8.5 \%$ & $8.2 \%$ & $0.0 \%$ \\
\hline Mean & 3.04 & 2.84 & 3.24 & 3.05 \\
\hline $\begin{array}{l}\text { Standard } \\
\text { Error }\end{array}$ & 0.08 & 0.13 & 0.11 & 0.15 \\
\hline
\end{tabular}

From the data in Table 7, we can also observe that the acceptance level of public transport users and active commuters (Bike and Walk) is higher than that of drivers. This may be due to the low impact to active commuters as the former is financially less affected than the latter.

A linear regression analysis is further conducted between the participants' opinion on the toll highways and congestion-pricing. Taking the former as independent variable and the latter as dependent variable, the coefficient of the variable is 0.486 , while the p-value for the regression is $6.6 \cdot 10^{-8}$. It statistically validates that the acceptance level on toll highways can significantly affect that of the congestion-pricing. Thus, enhancing the acceptance level of the toll highways will improve commuters' opinion on the new congestion-pricing scheme.

\subsection{Potential measures to improve acceptance}

A current estimated acceptance level of $42 \%$ suggests that some measures are needed to improve the level of support of congestion-pricing. The survey also collected the participants' opinion on the allocation of toll revenue. The questions analyzed in this section were based on a five point scale as follows: 1 - Strongly Disagree, 2 - Disagree, 3 - Neutral, 4 - Agree, 5 - Strongly Agree. In this survey, respondents were asked to indicate their agreement with two statements regarding the use of revenue;

- it should be used to improve public transport services and road infrastructure (mean $=4.15$, $\mathrm{SE}=0.08$;

- it should be used to improve the environment $($ mean $=3.26, \mathrm{SE}=0.08)$.

Table 6. Coefficients and p-values associated congestion-pricing support

\begin{tabular}{|c|c|c|c|c|c|c|c|c|c|c|c|c|}
\cline { 2 - 13 } \multicolumn{1}{c|}{} & \multicolumn{3}{c|}{ Drive } & \multicolumn{4}{c|}{ PT } & \multicolumn{3}{c|}{ Bike and walk } & \multicolumn{3}{c|}{ Overall } \\
\hline Factor & A & B & C & A & B & C & A & B & C & A & B & C \\
\hline Coeff. & 1.744 & 0.261 & -0.106 & 0.699 & 0.854 & -0.069 & 0 & 1.075 & -0.074 & 1.072 & 0.604 & -0.087 \\
\hline$p$-value & $<0.0001$ & 0.3416 & $<0.0001$ & 0.0077 & 0.001 & $<0.0001$ & 1 & 0.0465 & 0.0012 & $<0.0001$ & 0.0015 & $<0.0001$ \\
\hline
\end{tabular}


The mean of 4.15 for use of revenue to improve public transport services and road infrastructure was found to be significantly larger than the mean of 3.26 for use of revenue to improve the environment. Based on this, it can be suggested that a congestion-pricing scheme in Melbourne should commit to devoting revenue toward public transport and road infrastructure improvements rather than environmental improvements. Use of revenue to improve public transport has been found to be important in influencing public acceptance of congestion-pricing in other cities (e.g. New York).

The response to the statement regarding the ability of the existing public transport system to cope with additional passengers was consistent with the above findings. Respondents generally do not believe that the public transport system is capable of coping with increased volume of passengers $($ mean $=1.95, \mathrm{SE}=0.07)$. As viable alternatives to driving are an important factor in increasing public acceptance of congestion-pricing schemes, it is recommended that public transport system upgrades occur prior to or in conjunction with implementation of a scheme. A well-developed public transport system with ample capacity to accommodate more demand is also taken as a prerequisite of congestion-pricing in Stockholm (Eliasson 2008, 2009).

Responses to the questions regarding the ability of a congestion-charging scheme to reduce congestion (mean $=3.48, \mathrm{SE}=0.08$ ) and to reduce emissions (mean $=3.40, \mathrm{SE}=0.07$ ) are not significant considering that 3.00 is the Neutral case. Such sort of doubts about the prospect and efficiency of a new policy, like congestion-pricing, is observed to be common among residents in many other cities. Compared with the changes, people prefer the status quo to unfamiliar changes (Hensher, Li 2013). The real implementations of congestion-pricing in many cities (including Singapore, London, Stockholm and Milan) have strongly supported the capability and efficiency of congestion-pricing. Hence, an information campaign and/or trial are/is needed to raise awareness of the benefits of a congestion-charging scheme. Table 8 shows the change of acceptance level after the implementations of pricing schemes across the world. This indicates that the people are, in many cases, shortsighted regarding the benefits of congestion-pricing.

The experience of real benefits is taken as a key factor in improving public acceptance of congestion-pricing in the study of Hensher and Li (2013), followed by some other factors; cognitive dissonance; political party preferences; international impacts; media influence. In addition, the experience in other cities showed that a trial can provide real experience to the general public as well as politicians, regarding the benefits of congestionpricing, and eventually changed their perspectives from negative to positive.

\subsection{Discussion onl factors and measures}

One additional factor to consider is the current method of toll collection in Melbourne's toll highways. Tolls are collected through the use of e-tag technology (or automatic number plate recognition for vehicles with no etag) at gantries. Although a number of cities experienced issues regarding privacy in toll collection (e.g., Hong Kong), this is not expected to be an issue in Melbourne. The toll collection for a congestion-charging scheme could be set up to use the same or a similar e-tag system. Many road users in Melbourne are already familiar with the e-tag technology and there are no privacy issues currently identified with the system. Familiarity with the system is also expected to increase the level of public acceptance.

The need to improve the public transport system in the event of a congestion-pricing scheme being implemented has already been discussed. However, there is also the need to upgrade the road network bypassing the city of Melbourne before a scheme can be introduced. Road network users who want to drive to the other side of the city, but do not have a destination within the CBD, need effective routes. Roads such as the Westgate Bridge, Monash Freeway, CityLink and the Western Ring Road need to be capable of effectively moving traffic around the city area. Investigations into the expected increase in traffic on these roads need to be assessed against the capacity.

Equity issue is also an important factor that affects the acceptance level of congestion-pricing; especially for the drivers with low income who claim that the pricing makes road a privilege to the rich people. In addition, for people living or working in the city area, a cordonbased or area-based charge is deemed as unfair for them, since they have no alternative non-tolled options for destination or route choice. For this group of people, the concept of tradable credit can be implemented (Yang, Wang 2011), and people living or working in the city with lower household income can be provided with more tradable credits.

Table 8. Change of public support rate after implementations (Hensher, Li 2013)

\begin{tabular}{|l|c|c|c|c|}
\hline \multicolumn{1}{|c|}{ City } & Year of implementation & Ex ante support rate [\%] & Survey time after implementation & Ex post support rate [\%] \\
\hline Bergen & 1986 & 49 & 1 year & 63.5 \\
\hline Oslo & 1990 & 30 & 1 year & 36 \\
\hline Trondheim & 1991 & 28 & 2 months & 52 \\
\hline London & 2003 & 40 & 6 months & over 50 \\
\hline Stockholm & 2007 & 36 & 4 months & 66 \\
\hline
\end{tabular}




\section{Conclusions and recommendations}

Based on the findings obtained from the survey results and comparisons made with previous studies, there are a number of points that should be considered for a congestion-charging scheme in Melbourne. These points may help to increase the level of public acceptance from its current level of $42 \%$ as noted in this study. A higher acceptance rate is expected if a congestion-pricing scheme is to be implemented.

An information campaign is recommended to improve the level of understanding and confidence regarding what results will be obtained from a new congestionpricing scheme. Further research into respondents' attitudinal factors is required to ensure that an information campaign is targeted and run as efficiently as possible. It is also recommended that a trial congestion-pricing scheme should be run in Melbourne prior to a referendum for a congestion-pricing scheme. Previous trials have shown that the level of acceptance increases when the benefits are realized. In addition, a congestion-pricing scheme proposal can be a good starting point to begin discussions and raise awareness before the campaign and/or trial.

The public should made aware of how the revenue is to be used from a scheme and it is recommended that the revenue should be used to improve public transport and road infrastructure, rather than the environment. This is expected to increase the level of public acceptance of a congestion-charging scheme in Melbourne. In addition, the public do not believe that the current public transport system is capable of accepting the additional passengers. The public transport system should be upgraded prior to or at the same time as a congestionpricing scheme is implemented. This will increase public acceptance by providing a viable alternative to driving.

Additionally, the roads carrying traffic around Melbourne, not through the CBD, need to be capable of efficiently moving additional traffic. Roads such as the Westgate Bridge and the Western Ring Road will need to be modeled to ensure the viability of this option. A congestion-charging scheme should make use of the e-tag technology currently used in Melbourne on toll roads. The public is already familiar with this system and as noted from the previous studies, familiarity with the system is expected to increase public acceptance.

It should be noted that a sample size of 169 presented in this paper is limited in terms of public opinion, to provide more representative conclusions on the viability of congestion-pricing in Melbourne. In the future, together with the local authority and consultant teams, it is recommended to conduct a citywide survey or referendum for the public acceptance of the congestion-pricing in Melbourne. Nevertheless, the design of questionnaire and the key findings reported in this paper will be of considerable significance for such a citywide survey in Melbourne or any other cities in the future.

\section{Acknowledgements}

This research was partially funded by the Faculty of Engineering Seed Funding Scheme at Monash University (Australia) and National Natural Science Foundation of China (No. 71501038).

The efforts by Ms. Xiaoying Cao, Ms. Alisa Redsell and Mr. Sam Hughes on collecting survey data in Melbourne (Australia) are appreciated.

\section{References}

ABS. 2014. Australian Bureau of Statistics (ABS). Available from Internet: http://www.abs.gov.au

Ahmed, B. 2011. Manchester congestion charge scheme: a review, Journal of Civil Engineering and Construction Technology 2(11): 236-241. http://dx.doi.org/10.5897/JCECT11.025

CityLink. 2014. CityLink Melbourne Limited. Available from Internet: http://www.citylink.com.au

Clarke, H.; Hawkins, A. 2006. Economic framework for Melbourne traffic planning, Agenda 13(1): 63-80.

De Borger, B.; Proost, S. 2012. A political economy model of road pricing, Journal of Urban Economics 71(1): 79-92. http://dx.doi.org/10.1016/j.jue.2011.08.002

Di Ciommo, F.; Monzón, A.; Fernandez, A. 2010. Measuring the acceptability of interurban road pricing among different groups of stakeholders. The case of Spain, in TRB 89th Annual Meeting Compendium of Papers, 10-14 January 2010, Washington, DC, 1-22.

Do, M.; Kobayashi, K. 2000. Route navigation by state-contingent road pricing, KSCE Journal of Civil Engineering 4(3): 119-128. http://dx.doi.org/10.1007/BF02830865

Eliasson, J. 2009. A cost-benefit analysis of the Stockholm congestion charging system, Transportation Research Part A: Policy and Practice 43(4): 468-480. http://dx.doi.org/10.1016/j.tra.2008.11.014

Eliasson, J. 2008. Lessons from the Stockholm congestion charging trial, Transport Policy 15(6): 395-404. http://dx.doi.org/10.1016/j.tranpol.2008.12.004

Gaunt, M.; Rye, T.; Allen, S. 2007. Public acceptability of road user charging: the case of Edinburgh and the 2005 referendum, Transport Reviews 27(1): 85-102. http://dx.doi.org/10.1080/01441640600831299

Goh, M. 2002. Congestion management and electronic road pricing in Singapore, Journal of Transport Geography 10(1): 29-38. http://dx.doi.org/10.1016/S0966-6923(01)00036-9

Hamer, P.; Currie, G.; Young, W. 2011. Parking price policies: a review of the Melbourne congestion levy, in Australasian Transport Research Forum 2011 Proceedings, 28-30 September 2011, Adelaide, Australia, 1-16.

Hau, T. D. 1990. Electronic road pricing: developments in Hong Kong 1983-1989, Journal of Transport Economics and Policy 24(2): 203-214.

Hensher, D. A.; Li, Z. 2013. Referendum voting in road pricing reform: a review of the evidence, Transport Policy 25: 186-197. http://dx.doi.org/10.1016/j.tranpol.2012.11.012

Hensher, D. A.; Rose, J. M.; Collins, A. T. 2013. Understanding buy-in for risky prospects: incorporating degree of belief into the ex-ante assessment of support for alternative road pricing schemes, Journal of Transport Economics and Policy 47(3): 453-473. 
Ieromonachou, P.; Potter, S.; Warren, J. P. 2006. Norway's urban toll rings: evolving towards congestion charging?, Transport Policy 13(5): 367-378.

http://dx.doi.org/10.1016/j.tranpol.2006.01.003

Jaensirisak, S.; Wardman, M.; May, A. D. 2005. Explaining variations in public acceptability of road pricing schemes, Journal of Transport Economics and Policy 39(2): 127-153.

Jakobsson, C.; Fujii, S.; Gärling, T. 2000. Determinants of private car users' acceptance of road pricing, Transport Policy 7(2): 153-158. http://dx.doi.org/10.1016/S0967-070X(00)00005-6

Kroes, E. P.; Sheldon, R. J. 1988. Stated preference methods: an introduction, Journal of Transport Economics and Policy 22(1): 11-25.

Lawphongpanich, S.; Hearn, D. W.; Smith, M. J. 2006. Mathematical and Computational Models for Congestion Charging. Springer. 240 p. http://dx.doi.org/10.1007/0-387-29645-X

Litman, T. 2011. London Congestion Pricing: Implications for Other Cities. Victoria Transport Policy Institute. 14 p. Available from Internet: http://www.vtpi.org/london.pdf

Liu, Z.; Meng, Q.; Wang, S. 2013. Speed-based toll design for cordon-based congestion pricing scheme, Transportation Research Part C: Emerging Technologies 31: 83-98. http://dx.doi.org/10.1016/j.trc.2013.02.012

Liu, Z.; Meng, Q.; Wang, S. 2014a. Variational inequality model for cordon-based congestion pricing under side constrained stochastic user equilibrium conditions, Transportmetrica A: Transport Science 10(8): 693-704.

http://dx.doi.org/10.1080/23249935.2013.821228

Liu, Z.; Wang, S.; Meng, Q. 2014b. Optimal joint distance and time toll for cordon-based congestion pricing, Transportation Research Part B: Methodological 69: 81-97. http://dx.doi.org/10.1016/j.trb.2014.08.005

Liu, Z., Wang, S.; Meng, Q. 2014c. Toll pricing framework under logit-based stochastic user equilibrium constraints, Journal of Advanced Transportation 48(8): 1121-1137. http://dx.doi.org/10.1002/atr.1255

Luk, J.; Chung, E. 1997. Public acceptance and technologies for road pricing, Research Report ARR 307: 1-26.

Meng, Q.; Liu, Z. 2012. Impact analysis of cordon-based congestion pricing on mode-split for a bimodal transportation network, Transportation Research Part C: Emerging Technologies 21(1): 134-147.

http://dx.doi.org/10.1016/j.trc.2011.06.007

Meng, Q.; Liu, Z. 2011. Trial-and-error method for congestion pricing scheme under side-constrained probit-based stochastic user equilibrium conditions, Transportation 38(5): 819-843. http://dx.doi.org/10.1007/s11116-011-9346-9

Meng, Q.; Liu, Z.; Wang, S. 2012. Optimal distance tolls under congestion pricing and continuously distributed value of time, Transportation Research Part E: Logistics and Transportation Review 48(5): 937-957.

http://dx.doi.org/10.1016/j.tre.2012.04.004

Phang, S.-Y.; Toh, R. S. 1997. From manual to electronic road congestion pricing: the Singapore experience and experiment, Transportation Research Part E: Logistics and Transportation Review 33(2): 97-106.

http://dx.doi.org/10.1016/S1366-5545(97)00006-9

Pigou, A. C. 1920. The Economics of Welfare. Macmillan and Co. 1024 p.
Qu, X.; Wang, S.; Zhang, J. 2015. On the fundamental diagram for freeway traffic: A novel calibration approach for singleregime models, Transportation Research Part B: Methodological 73: 91-102.

http://dx.doi.org/10.1016/j.trb.2015.01.001

Rentziou, A.; Milioti, C.; Gkritza, K.; Karlaftis, M. G. 2011. Urban road pricing: modeling public acceptance, Journal of Urban Planning and Development 137(1): 56-64. http://dx.doi.org/10.1061/(ASCE)UP.1943-5444.0000041

Rotaris, L.; Danielis, R.; Marcucci, E.; Massiani, J. 2010. The urban road pricing scheme to curb pollution in Milan, Italy: description, impacts and preliminary cost-benefit analysis assessment, Transportation Research Part A: Policy and Practice 44(5): 359-375.

http://dx.doi.org/10.1016/j.tra.2010.03.008

Santos, G.; Shaffer, B. 2004. Preliminary results of the London congestion charging scheme, Public Works Management and Policy 9(2): 164-181.

http://dx.doi.org/10.1177/1087724X04268569

Santos, G. 2005. Urban congestion charging: a comparison between London and Singapore, Transport Reviews 25(5): 511-534. http://dx.doi.org/10.1080/01441640500064439

Schaller, B. 2010. New York City's congestion pricing experience and implications for road pricing acceptance in the United States, Transport Policy 17(4): 266-273. http://dx.doi.org/10.1016/j.tranpol.2010.01.013

Schuitema, G.; Steg, L.; Forward, S. 2010. Explaining differences in acceptability before and acceptance after the implementation of a congestion charge in Stockholm, Transportation Research Part A: Policy and Practice 44(2): 99-109. http://dx.doi.org/10.1016/j.tra.2009.11.005

Seik, F. T. 2000. An advanced demand management instrument in urban transport: electronic road pricing in Singapore, Cities 17(1): 33-45. http://dx.doi.org/10.1016/S0264-2751(99)00050-5

Sturcke, J. 2008. Manchester says no to congestion charging, The Guardian, 12 December 2008. Available from Internet: http://www.theguardian.com/politics/2008/dec/12/congestioncharging-transport

Tezcan, H. 2012. Using parking pricing as a travel demand management tool at a university campus: an example for Istanbul technical university, Transportation Letters 4(3): 181-192. http://dx.doi.org/10.3328/TL.2012.04.03.181-192

Wang, S.; Meng, Q.; Liu, Z. 2013. Fundamental properties of volume-capacity ratio of a private toll road in general networks, Transportation Research Part B: Methodological 47: 77-86. http://dx.doi.org/10.1016/j.trb.2012.09.006

Wang, S.; Meng, Q.; Yang, H. 2013. Global optimization methods for the discrete network design problem, Transportation Research Part B: Methodological 50: 42-60. http://dx.doi.org/10.1016/j.trb.2013.01.006

Yang, H.; Huang, H.-J. 2005. Mathematical and Economic Theory of Road Pricing. Elsevier Science. $486 \mathrm{p}$.

Yang, H.; Wang, X. 2011. Managing network mobility with tradable credits, Transportation Research Part B: Methodological 45(3): 580-594. http://dx.doi.org/10.1016/j.trb.2010.10.002 